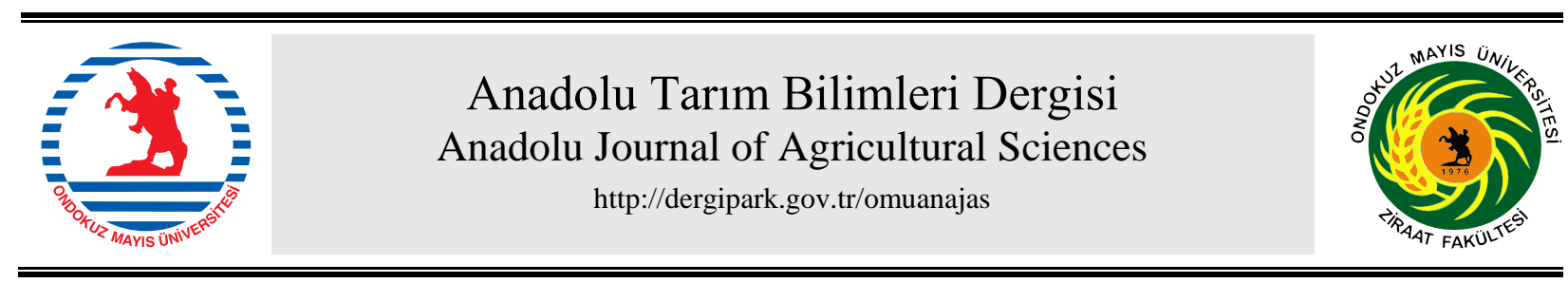

Araştırma/Research

Anadolu Tarım Bilim. Derg./Anadolu J Agr Sci, 35 (2020)

ISSN: 1308-8750 (Print) 1308-8769 (Online)

doi: $10.7161 /$ omuanajas.615474

\title{
Organik madde uzaklaştırılmasının parçacık büyüklük dağılımına etkileri
}

\author{
Nurullah Acir ${ }^{a^{*}}$, Hikmet Günal ${ }^{\mathrm{b}}$, İsmail Çelik ${ }^{\mathrm{c}}$ \\ ${ }^{a}$ Kırşehir Ahi Evran Üniversitesi, Ziraat Fakültesi, Toprak Bilimi ve Bitki Besleme Bölümü, Kırşehir, Türkiye \\ ${ }^{b}$ Tokat Gaziosmanpaş Üniversitesi, Ziraat Fakültesi, Toprak Bilimi ve Bitki Besleme Bölümü, Tokat, Türkiye \\ ${ }^{c}$ Çukurova Üniversitesi, Ziraat Fakültesi, Toprak Bilimi ve Bitki Besleme Bölümü, Adana, Türkiye
}

*Sorumlu yazar/corresponding author: nurullah.acir@ahievran.edu.tr

Geliş/Received 04/09/2019 Kabul/Accepted 25/11/2019

\begin{abstract}
ÖZET
Toprakta devam eden birçok fiziksel, kimyasal ve biyolojik süreç üzerine önemli düzeyde etkiye sahip olan parçacık büyüklük dağılımının doğru belirlenmesi, süreçler hakkında daha doğru yorum yapılabilmesini mümkün kılacaktır. $\mathrm{Bu}$ çalışmada, organik madde $(\mathrm{OM})$ uzaklaştırılması ön muamelesinin kil içerikleri \%18.8 ile \%83.4 arasında değişen 80 toprağın parçacık büyüklük dağılımı üzerine etkileri incelenmiş ve OM uzaklaştırmasının gerekli olup olmadığı tartışılmıştır. Topraklar kil $(<40 \%, \% 40-60$ ve $>60 \%)$ ve OM (\%0-1, \%1-2, \%2-4 ve >\%4) içeriklerine göre gruplara ayrılarak OM uzaklaştırmanın etkileri değerlendirilmiştir. OM uzaklaştırmanın beş farklı kum fraksiyonuna $(53 \mu$, $106 \mu, 250 \mu, 500 \mu$ ve $1000 \mu$ ) etkisi de bu çalışma kapsamında incelenmiştir. OM madde içeriği \%0.17 ile $6.78 \%$ arasında değişmektedir. Hidrojen peroksit ile OM uzaklaştırılması sonrasında kum ve kil içerikleri istatistiksel olarak önemli düzeyde değişmiştir. OM uzaklaştırılması ile toprakların kil ve silt içeriği artarken, kum içeriğinde $\mathrm{OM}$ içeriği \%1'in üzerinde olan topraklarda önemli düzeyde düşüş gerçekleşmiştir. Kum fraksiyonlarında, orta kum $(250 \mu)$ boyutundaki artışa karşılık ince $(106 \mu)$ boyuttaki kum miktarında önemli düzeyde azalma tespit edilmiştir. Sonuçlar, OM içeriği \%1'in üzerinde olan topraklarda OM uzaklaştırılmasının, tekstür bileşenlerini önemli düzeyde değiştirdiğini göstermiştir. Uzaklaştırma olmadan yapılan tekstür analizinde kil ve silt içeriklerinin daha düşük, kum içeriğinin ise daha yüksek olacağı unutulmamalıdır. Bu nedenle, toprağın birçok önemli fonksiyonunun gerçekleşmesinde etkili olan parçacık büyüklük dağılımının doğru belirlenmesi adına tekstür analizine başlamadan önce OM uzaklaştırılmasının standart bir ön işlem haline getirilmesi gerekmektedir.
\end{abstract}

\section{Effects of organic matter removal on particle size distribution}

\section{ABSTRACT}

Accurate determination of the particle size distribution, which has significant impacts on many physical, chemical and biological processes in soil, will enable a more accurate interpretation of the processes. In this study, the effects of organic matter (OM) removal pretreatment on the particle size distribution of 80 soil samples which have a clay content ranging from 18.8 to $83.4 \%$ were investigated to determine the necessity of OM removal pretreatment. The effect of OM removal was discussed by separating soil samples into clay $(<40 \%, 40-60 \%$ and $>60 \%)$ and OM $(0-1 \%, 1-2 \%, 2-4 \%$ and $>4 \%)$ group contents. The effect of OM removal on five different sand fractions $(53 \mu, 106 \mu, 250 \mu, 500 \mu$ and $1000 \mu$ ) was also investigated in this study. The mean OM content was $2.48 \%$ and ranged from 0.17 to $6.78 \%$. Sand and clay contents of soil samples significantly changed after the removal of OM with hydrogen peroxide. The removal of OM caused an increase in clay and silt contents, while sand content significantly decreased in soils with an OM content of higher than 1\%. Fine sand fraction $(106 \mu)$ significantly decreased despite an increase in $250 \mu$ size sand fraction. The results showed that removal of $\mathrm{OM}$ with an $\mathrm{OM}$ content of higher than $1 \%$ significantly changes the particle size distribution. If soil texture is determined without removal of OM, clay and silt contents will be lower and the sand content will be higher than the actual case. Therefore, the removal of OM should be set as a standard
Anahtar Sözcükler: Toprak tekstürü Organik madde Hidrojen peroksit Kum fraksiyonu Ön muamele
Keywords: Soil texture Organic matter Hydrogen peroxide Sand fraction Pretreatment

(C) OMU ANAJAS 2020 
pretreatment procedure before starting the texture analysis in order to accurately determine the particle size distribution which is crucial for many important soil functions.

\section{Giriș}

Parçacık büyüklük dağılımı (tekstür) suyun tutulması, hareketi ve besin elementlerinin döngüsü gibi çeşitli fonksiyonlara etkileri yanında toprak içerisindeki canlıların yaşamında da dolaylı olarak rol oynamaktadır. (Hillel, 1980; Filgueira et al. 2006; Shi et al. 2012; Blott ve Pye, 2012; Dobrowolski et al. 2012; Kabala ve Zapart, 2012). Diğer birçok fiziksel, kimyasal ve biyolojik özellik gibi arazi içi uygulamalar veya doğal olaylar ile kısa süre içerisinde değişmesi mümkün olmayan tekstür (Skopp, 1999), toprak ile ilgili araştırmalarda belirlenmesi istenen en temel özellik olarak kabul edilmektedir. Tekstür, su ve rüzgâr erozyonu, toprak üretkenliği, besin elementlerinin, pestisitlerin ve diğer kirleticilerin tutulması veya yıkanmasını kontrol etmesi nedeni ile toprak kalitesi çalışmalarında da yaygınlıkla belirlenmesi istenen bir özelliktir (Filgueira et al. 2006; Bayat et al. 2015).

Toprakların tekstür içeriklerinin bilinmesi diğer birçok özelliğin değerlendirilmesi ve bitkisel üretim açısından yorumlamada oldukça önemlidir. Fiziksel toprak özelliklerinden; hacim ağırlığı (Aşkın ve Özdemir, 2003), parçacık yoğunluğu (Schjonning et al. 2017), agregat stabilitesi (Bronick ve Lal, 2005), spesifik yüzey alanı (Erşahin ve ark. 2006), toprak havalanması (Horn ve Smucker, 2005), su ve çözeltilerin hareketi (Karup et al. 2016), gözeneklilik (Nimmo, 2004), şişme ve büzülme özellikleri (Gray ve Allbrook, 2002), toprak rengi (Günal et al. 2008; Kone et al. 2009) ile toprağın tekstürü arasında oldukça önemli iliş̧kiler rapor edilmiştir. Toprak tekstürü aynı zamanda katyon değişim kapasitesi (Erşahin ve ark. 2006), organik karbon içeriği (Broersma ve Lavkulich, 1980), kimyasalların adsorbe olması (Hillel, 1980) ve tamponlama kapasitesi gibi çeşitli kimyasal özellikler ve biyokütle üretimi (Chiu et al. 2006), organik maddenin parçalanması (Brady ve Weil, 2010), mikrobiyal aktivite (Hamarshid et al. 2010; Walkiewicz et al. 2012) ve azotun mineralizasyonu (Burgos et al. 2006) gibi biyolojik özellikler ile de ilişkilendirilmiştir. Toprakta gerçekleşen bazı fiziko-kimyasal süreçlerin tahmin edilmesi (Hajnos et al. 2013; Mohammadi ve MeskiniVishkaee, 2013) ve pedotransfer fonksiyonlarının kullanıminda da (Lamorski et al. 2008; Sepaskah ve Tafteh, 2013) toprak tekstürü aktif bir şekilde kullanılmaktadır.

En temel fiziksel özellik olarak kabul edilen toprak tekstürü, farklı disiplinlerden bilim insanları, mühendisler ve uygulayıcılar arasinda ortak bir dil olarak görev yaparak iletişimin kolaylaşmasını sağlamaktadır (Filgueira et al. 2006). Kum (0.02-2 mm), silt $(0.002-0.02 \mathrm{~mm})$ ve kil $(<0.002 \mathrm{~mm})$ parçacıklarının oransal miktarlarını ifade eden (Bouyoucos, 1962) toprak tekstürünün belirlenmesinde sedimentasyon testi ve lazer difraksiyon metodu şeklinde iki ana yöntem yaygın olarak kullanılmaktadır (Polakowski et al. 2014). Sedimentasyon testleri, Stoke yasasını esas almakta olan Bouyoucos hidrometresi veya Pipet yöntemi ile uygulanmaktadır (Kilmer ve Alexander, 1949). Genellikle 0-2.0 mm arasındaki parçacıklar kum, silt ve kil parçalarından oluşmakla birlikte, kum boyutundaki parçacıların çok sayıdaki kil veya silt parçacığının birleşmesinden oluşmuş agregatları da içerdiği bilinmektedir (Stanchi et al. 2008). Kum, silt ve kil parçacıkları, yapıştırma özeliği bulunan daha az çözünür tuzlar (kalsiyum karbonat, alçı vb.), demir alüminyum oksitler ya da organik bileşiklerin etkisi ile birbirlerine bağlanarak agregatları oluştururlar (Gunal ve ark. 2011). $\mathrm{Bu}$ nedenle, Gee ve Or (2002), toprakların parçacık büyüklük dağılımlarını belirlemek için öncelikle toprağın organik madde $(\mathrm{OM})$, seskioksitler, karbonatlar ve diğer çimentolayıcı maddelerin uzaklaştırılması için ön muamele işlemlerinden geçirilmeleri gerektiğini bildirmektedirler. Bununla birlikte, toprak analizi yapan laboratuvarların çok büyük çoğunluğu tekstür analizi öncesinde herhangi bir ön muamele yapmamaktadır. Parçacıkları disperse etmekte kullanılan kimyasalın gücü agreatları parçalamaya yetmediği durumlarda, toprağın gerçek parçacık büyüklük dağılımının belirlenmesi de mümkün olamamaktadır.

$\mathrm{Bu}$ nedenle, geçekleştirilen çalışma ile kum, kil ve silt parçacıklarının çimetolanmasında etkin rol oynayan organik maddenin uzaklaştırılmasının toprakların parçacık büyüklük dağılımına etkisi araştırılmıştır. Tekstür analizi öncesinde OM uzaklaştırılmasının gerekli olup olmadığı sorusuna yanıt aranan bu çalışmada ayrıca, hangi OM içeriğine sahip topraklar için OM uzaklaştırması yapılmalıdır? sorusu da cevaplanmaya çalışılmıştır.

\section{Materyal ve Yöntemler}

\subsection{Materyal}

Tokat, Kayseri ve Niğde illerinde yer alan çeşitli tarım arazileri ve meralardan $0-20 \mathrm{~cm}$ derinlikten alınan, organik madde ve kil içeriği açısından geniş bir varyasyon gösteren 80 adet toprak örneği bu çalışmada materyal olarak kullanılmıştır. Bu toprakların 40 adedi Tokat-Kazova'da tarla bitkileri ve sebze bitkileri ekili alanlar ile mera arazilerinde, 13 adedi Kayseri'de Sultan Sazlığı etrafinda yer alan mera arazilerinden ve 27 adedi ise Niğde ilinde tarla bitkileri yetiştirilen araziler ile mera olarak kullanılan alanlardan alınmıştır. Toprak örneklemelerini gösteren harita Şekil 1'de sunulmuştur. 


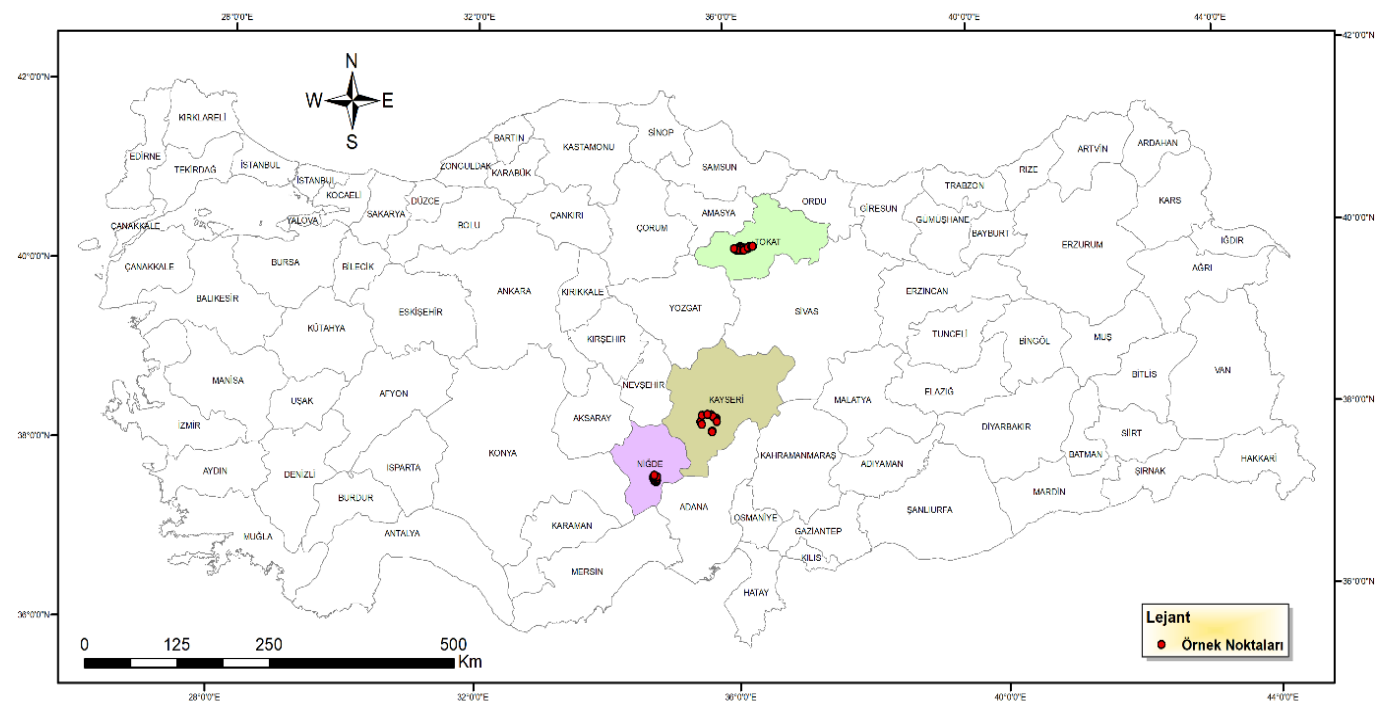

Şekil 1. Toprak örnekleme yerleri

Figure 1. The locations of soil sampling

\subsection{Yöntem}

Araziden alınan toprak örnekleri oda sicaklığında kurutulmuş, içerisindeki kök, bitki atıkları ve çakıllar temizlendikten sonra tahta tokmaklar ile ögütülmüş ve $2.00 \mathrm{~mm}$ 'lik elekten geçirilerek analize hazırlanmıştır. Parçacık büyüklük dağılımı ile ilgili çalışmalar iki aşamalı olarak gerçekleştirilmiş̧ir. Öncelikle OM uzaklaştııılmadan toprakların parçacık büyüklük dağılımı Bouyoucos, hidrometre yöntemine göre belirlenmiştir (Gee ve Bauder, 1986).

$\mathrm{Bu}$ aşamada kum, kil ve silt oranları belirlendikten sonra tekstür silindirinde bulunan örnekler $53 \mu, 106 \mu, 250 \mu, 500 \mu$ ve $1000 \mu$ büyüklüğünde 5 farklı elek yardımı ile kum fraksiyonlarına ayrılmıştır. İkincisi aşamada ise beher içerisine tartılan örnekler, 1sitmalı su banyosuna yerleştirilmiş ve \%30'luk hidrojen peroksit $\left(\mathrm{H}_{2} \mathrm{O}_{2}\right)$ ilave edilerek OM'nin uzaklaştırılması sağlanmıştır. Hidrojen peroksit muamelesinde köpürmenin bittiği noktada, birinci aşamada belirtilen tekstür analizleri yapılmış ve sonrasında 5 ayrı kum fraksiyonu belirlenmiştir.

Toprak örneklerinde OM içeriği Nelson ve Sommers (1982) tarafindan belirtilen "Modifiye Edilmiş Walkley-Black" metoduna göre belirlenmiştir. Agregat stabilitesi, Kemper ve Rosenau (1986)'a göre 2.0 ile $1.0 \mathrm{~mm}$ arasında kalan toprak parçacıklarının islak eleme yöntemine göre elenmesi sonrasında hesaplanmıştır. Kireç içeriği, Scheibler kalsimetresi yöntemine göre belirlenmiştir (Kacar, 1994). Toprak reaksiyonu (pH) ve elektriksel iletkenlik (EC), 1:2.5 toprak/su süspansiyonunda $\mathrm{pH} / \mathrm{EC}$ metre aleti ile ölçülmüştür (Rhoades et al. 1999). Katyon değişim kapasitesi, $1.0 \mathrm{~N}$ amonyum asetat $(\mathrm{pH}=7.0)$ yöntemine göre belirlenmiştir (Jackson, 1958).

\subsection{Veri Değerlendirmeleri}

Çalışma alanı toprak özelliklerine ait en küçük, en büyük, ortalama, standart sapma ve varyasyon katsayısı şeklindeki tanımlayıcı parametreler SPSS programı (SPSS 21) ile hesaplanmıştır. Organik madde uzaklaştırma öncesi ve sonrası tekstür bileşenleri ve 5 faklı kum fraksiyonu için de tanımlayıcı istatistikler hesaplanmıştır. Organik madde uzaklaştırması ile ortaya çıkan farklılığın istatistiksel olarak önemli olup olmadığını anlamak için eşleştirilmiş t-testi yapılmıştır.

\section{Bulgular ve Tartış̧ma}

Araştırmada kullanılan toprak örneklerinin bazı fiziksel ve kimyasal özeliklerine ait tanımlayıcı istatistik parametreleri Çizelge 1'de verilmiştir. Çalışılan toprakların ortalama organik maddesi (OM) $\% 2.48$ olup, \%0.17 ile 6.78 arasında değişmektedir. Veri setindeki bir özelliğin değişkenliğini ifade etmekte kullanılan varyasyon katsayıs (VK) $\% 15^{\prime}$ ten küçük olduğunda az değişken, $\geq \% 15$ ile $\leq \% 35$ arasında ise orta değiş̧ken ve $\geq \% 35$ olduğunda ise çok değişken olarak değerlendirilmektedir (Wilding, 1985). Buna göre çalışılan topraklar arasında OM içeriği oldukça yüksek düzeyde değişkenlik $(\mathrm{CV}=\%$ 71.4) göstermektedir. $\mathrm{Bu}$ durum $\mathrm{OM}$ uzaklaştırmasının etkisinin anlaşılması adına önemlidir. Organik madde içeriğinde olduğu gibi çalışılan toprakların kireç içeriği de yüksek düzeyde değişkenlik göstermekte olup ( $\mathrm{CV}=\%$ 75.9), \%2.22 (az kireçli) ile \%70.94 (aşırı kireçli) arasında değişmektedir. Topraklarda agregatlaşmayı sağlamayan bir diğer önemli özellik kireç içeriğidir ve parçacık dağılımın belirlenmeden önce 
uzaklaştırılması gerekmektedir (Günal ve ark. 2011). Fakat, bu çalışmada sadece organik maddenin parçacık büyüklük dağılımına olan etkisi araştırıldığından dolayı, kirecin uzaklaştırılması için herhangi bir ön işlem yapılmamıştır. Kireç ve OM ile birlikte toprakların tuzluluğunun göstergesi olarak kabul edilen elektriksel iletkenlik oldukça yüksek bir değişkenliğe $\quad(\mathrm{CV}=\%$ 138.5 $)$ sahiptir. Çalışılan topraklar içerisinde tuzsuz topraklar olduğu gibi şiddetli tuzluluk $\left(\mathrm{EC}=11.89 \mathrm{dS} \quad \mathrm{m}^{-1}\right)$ gösteren arazilerden (EC>4.0 dS m-1 olan yaklaşık 10 adet örnek) alınmış toprak örnekleri de bulunmaktadır. Agregat stabilitesi $(\mathrm{CV}=\% 21.1)$ ve katyon değişim kapasitesi $(\mathrm{CV}=\% 29.3)$ orta düzeyde değişkenlik göstermektedir. Değişkenliği en düşük $(\mathrm{CV}=\% \mathbf{0 6})$ toprak özelliği olan pH değerleri 7.07 ile 10.09 arasında değişmekte ve ortalama $\mathrm{pH}$ değeri 8.53'tür.

Çizelge 1. Toprakların bazı özelliklerine ait tanımlayıcı istatistikleri

Table 1. Descriptive statistics of some soil properties

\begin{tabular}{ccrrrrr}
\hline Toprak Özellikleri & \multirow{2}{*}{ Birim } & $\begin{array}{c}\text { En } \\
\text { Düşük }\end{array}$ & En Büyük & Ortalama & Standart sapma & Varyasyon Katsayıs1 \\
\hline Organik Madde & & 0.17 & 6.78 & 2.48 & 1.77 & 71.4 \\
Agregat Stabilitesi & $\%$ & 30.81 & 99.42 & 84.79 & 17.92 & 21.1 \\
Kireç & & 2.22 & 70.94 & 16.58 & 12.58 & 75.9 \\
\hline Elektriksel İletkenlik & $\mathrm{dS} \mathrm{m}^{-1}$ & 0.17 & 11.89 & 1.75 & 2.43 & 6.6 \\
\hline $\mathrm{pH}$ & & 7.07 & 10.09 & 8.53 & 0.56 & 29.3 \\
\hline Katyon Değişim & \multirow{2}{*}{${\text { me } 100 \mathrm{~g}^{-1}}^{-1}$} & 8.34 & \multirow{2}{*}{45.44} & 26.33 & 7.71 & \\
Kapasitesi & & & & &
\end{tabular}

Mineralojik ve bazı fiziksel toprak analizlerine başlamadan önce hidrojen peroksit (H2O2) kullanımı ile organik maddenin uzaklaştırılması tercih edilen en yaygın yöntemdir (Kunze ve Dixon, 1986; Mikutta et al. 2005). Kum, kil ve silt büyüklüğündeki mineral parçacıkların kümeleşmesine neden olan OM'yi uzaklaştırabilmek için tüm topraklar $\mathrm{H}_{2} \mathrm{O}_{2}$ ile muamele edilmiş ve uygulama öncesi ve sonrasındaki parçacık büyüklük dağılımına ait değerler Çizelge 2'de verilmiştir. Uygulanan $\mathrm{H}_{2} \mathrm{O}_{2}$, kum, kil ve silt parçacıkları arasında köprü görevi görerek agregatların oluşmasına neden olan organik maddenin uzaklaşmasını sağladığından kil ve silt içeriğinde artış gerçekleşmiş ve sırasıyla ortalama $\% 46.5$ 'den $\% 49.2$ 'ye ve $\% 24.5$ 'den $\% 25$ 'e yükselmiştir (Çizelge 2).

Çizelge 2. Organik madde uzaklaştırma öncesi ve sonrası kum, kil ve silt içeriklerine ait tanımlayıcı istatistikler Table 2. Descriptive statistics of sand, clay and silt contents before and after organic matter removal

\begin{tabular}{rrrrrrr}
\hline \multirow{3}{*}{ Önce } & En Düşük & En Büyük & Ortalama & $\begin{array}{r}\text { Standart } \\
\text { sapma }\end{array}$ & $\begin{array}{r}\text { Varyasyon } \\
\text { Katsay1s1 }\end{array}$ \\
& Kil & 18.8 & 83.4 & 46.5 & 16.7 & 35.85 \\
& Silt & 8.0 & 45.5 & 24.5 & 7.72 & 31.53 \\
& Kum & 3.7 & 69.2 & 29.0 & 17.1 & 58.84 \\
\hline \multirow{3}{*}{ Sonra } & OM-Kil & 19.7 & 88.9 & 49.2 & 15.97 & 32.50 \\
& OM-Silt & 7.1 & 49.5 & 25.0 & 8.51 & 34.02 \\
& OM-Kum & 2.9 & 63.1 & 25.9 & 16.02 & 61.97 \\
\hline
\end{tabular}

Sonuçlar, OM uzaklaştırılmadan tekstür belirlendiğinde kil içeriğinin olması gerekenden $\% 6$ ve silt içeriğinin ise $\% 2$ daha düşük olacağını göstermektedir. Jensen ve ark. (2017)'da toprak organik maddesi uzaklaştırılmadan elde edilecek kil içeriğinin olması gerekenden $\% 19$ ve silt içeriğinin ise $\% 30$ daha düşük olacağını rapor etmişlerdir. Elde ettiğimiz bulgulara benzer şekilde, Stanchi ve ark. (2008)'da OM uzaklaştırılması sonrasında kil ve silt içeriğinin önemli düzeyde arttığını rapor etmiştir. Bu artışın, kaba kum boyutundaki agregatlarda yer alan organik maddenin $\mathrm{H}_{2} \mathrm{O}_{2}$ uygulamas i ile okside olmasına bağlamışlardır. Araştırmacılar, kil partiküllerinin kum parçacıkları üzerinde film şeklinde veya kum parçacıkları arasında köprü şeklinde biriktiğini de rapor etmişlerdir. Jensen ve ark. (2017)'da standart olarak tavsiye edilen \%30'luk $\mathrm{H}_{2} \mathrm{O}_{2}$ kullanımının topraktaki organik maddenin \% 80-90'nını uzaklaştırmaya yettiğini belirtmektedir. Araştırmacılar $\mathrm{H}_{2} \mathrm{O}_{2}$ uygulamasının vermikulit, mika ve özellikle de smektit kil minerallerinin çözünmesine neden olduğunu bildirmişlerdir.

Hidrojen peroksit uygulamas1 sonrasinda toprakların kum içeriği ortalama \%29'dan \%25.9'a düşmüştür. Sonuçlar, özellikle kum boyutundaki bir kısım agregatların tekstür analizinde yaygın olarak kullanilan sodyum hekzametafosfat ile yeterince disperse edilemediğini göstermektedir. Kum büyüklüğündeki bu agregatlar, kum parçacıkları gibi kısa sürede çöktüğünden hesaplamada kum oranına 
dahil edilmektedir. Kum boyutundaki kil ve silt parçacıklarından oluşan agregatlar ile ilgili olarak, Bronick ve Lal (2005)'da kaba kum boyutundaki parçacıkların iyi disperse olmaları halinde hem kil hem de silt boyutundaki parçacıkların serbest kalarak miktarının artacağını rapor etmişlerdir.

Topraklarda OM'nin uzaklaştırılması sonrasında kum içeriğinde meydana gelen azalmanın hangi kum fraksiyonunda gerçekleştiğini belirlemek amacı ile $53 \mu, 106 \mu, 250 \mu, 500 \mu$ ve $1000 \mu$ boyutlarında açıklıkları olan 5 farklı elek kullanılarak kum fraksiyonları hesaplanmış ve sonuçlar Çizelge 3'de verilmiştir. Sonuçlara bakıldığında, $1000 \mu$ ve $250 \mu$ boyutundaki kum fraksiyonlarında ortalama olarak bir artış söz konusu iken diğer tüm fraksiyonlarda azalma meydana gelmiştir. Organik madde uzaklaştırmasının mineral parçacıkların dağılımına etkisini araştıran Scott ve Rothstein (2014), OM uzaklaştırılmasıyla kaba kum boyutundaki parçacıkların oranının \%60'dan \%45'e düştüğünü, bununla birlikte ince kum, silt ve kil içeriğinde ise artış olduğunu belirtmişlerdir. $\mathrm{Bu}$ çalışmada ise $1000 \mu$ ve $250 \mu$ boyutundaki kaba kum fraksiyonlarında sırası ile \%11 ve \%14'lük artışlar olmuş, diğer tüm fraksiyonlarda ise azalmalar meydana gelmiştir.

Çizelge 3. Organik madde uzaklaştırma öncesi ve sonrası kum fraksiyonlarına ait tanımlayıcı istatistikler Table 3. Descriptive statistics of sand fractions before and after organic matter removal

\begin{tabular}{|c|c|c|c|c|c|c|}
\hline & Fraksiyon & $\begin{array}{r}\text { En } \\
\text { Düşük }\end{array}$ & En Büyük & Ortalama & $\begin{array}{r}\text { Standart } \\
\text { sapma }\end{array}$ & $\begin{array}{r}\text { Varyasyon } \\
\text { Katsayis1 }\end{array}$ \\
\hline \multirow{6}{*}{ Önce } & $1000 \mu$ & 0.42 & 22.22 & 7.07 & 4.66 & 65.94 \\
\hline & $500 \mu$ & 5.14 & 45.71 & 17.52 & 8.05 & 45.96 \\
\hline & $250 \mu$ & 1.76 & 26.04 & 12.71 & 5.01 & 39.42 \\
\hline & $106 \mu$ & 10.69 & 54.88 & 34.68 & 11.73 & 33.83 \\
\hline & $53 \mu$ & 5.35 & 62.09 & 28.02 & 10.92 & 38.95 \\
\hline & Kum & 2.28 & 29.22 & 12.82 & 7.30 & 56.90 \\
\hline \multirow{6}{*}{ Sonra } & OM $1000 \mu$ & 0.41 & 29.54 & 7.94 & 5.53 & 69.58 \\
\hline & OM $500 \mu$ & 2.98 & 37.64 & 17.15 & 7.54 & 43.99 \\
\hline & OM $250 \mu$ & 1.94 & 42.05 & 14.75 & 7.72 & 52.34 \\
\hline & OM $106 \mu$ & 9.28 & 61.82 & 32.67 & 11.26 & 34.47 \\
\hline & OM $53 \mu$ & 6.64 & 60.04 & 27.49 & 10.91 & 39.69 \\
\hline & OM Kum & 2.25 & 27.18 & 11.00 & 6.46 & 58.72 \\
\hline
\end{tabular}

Organik maddenin uzaklaştırılması sonrasında farklı kil içeriğine sahip topraklarda meydana gelen değişimin belirlenmesi amacı ile örnekler kil içeriklerine göre $\leq \% 40,>\% 40$ ile $\leq \% 60$ arası ve $>$ $\% 60$ şeklinde 3 farklı grupta toplanmıştır. Kil gruplarında yer alan örneklerin OM öncesi ve sonras1 kil, silt ve kum fraksiyonlarına ait değerler eşleştirilmiş t-testi ile karşılaş̧tırılmış ve sonuçları Çizelge 4'de verilmiştir. Tüm örnekler birlikte değerlendirildiğinde OM uzaklaştırılmasının etkisinin kil ve kum içeriklerinde önemli düzeyde farkl1lığa neden olduğu görülmektedir. Organik maddenin uzaklaştırılması sonrasında kil içeriği arttığından negatif ve kum içeriği azaldığından dolayı pozitif değerler almıştır. Kil içeriğine göre ayrılan gruplara bakıldığında, ilk iki kil grubunda bu fark $\mathrm{P}<0.01$ düzeyinde önemli iken 3 . kil grubunda kil içeriğindeki farklılığın daha düşük düzeyde $(\mathrm{P}<0.05)$ gerçekleştiği belirlenmiştir (Çizelge 4). Kum içeriğinde de benzer bir durum söz konusudur. Kum içeriği her üç kil grubunda da azalmasına rağmen, 3 . kil grubundaki azalma istatistiksel açıdan önemsiz düzeyde kalmıştır. Kil içeriğindeki artışla birlikte OM uzaklaştırılması ile oluşan farklılığın azalması söz konusu olmuştur.
Organik madde uzaklaştırılması ile kum fraksiyonlarından $250 \mu$ boyutunda istatistiksel olarak önemli düzeyde $(\mathrm{P}<0.05)$ bir artış, bunun aksine ve $106 \mu$ boyutunda ise önemli düzeyde $(\mathrm{P}<0.05)$ azalma meydana gelmiştir. Kil gruplarına göre ayrılan örneklerde kum fraksiyonlarında meydana gelen değişimler için yapılan eşleştirilmiş t-testi sonuçları Çizelge 4'de sunulmuştur. Orta kum fraksiyonunu gösteren $250 \mu$ boyutundaki kumun artı̧s, OM'nin uzaklaştırılması ile daha iri olan kum parçacıklarını bir arada tutan bağın yok olduğu ve ayrılarak bu boyuta indirgendikleri anlaşılmaktadır. Bu değişim, $<\% 40$ kil içeren topraklarda istatistiksel olarak önemli iken özellikle de \%40-60 arasında kil içeren grupta çok küçük ve önemsiz düzeyde kalmıştır. İnce ve çok ince kum boyutlarında ise OM'nin uzaklaştırılması ile çoğunlukla bir azalma olduğu anlaşılmaktadır. Elde edilen sonuçlar geçmiş̧ araştırmalar ile benzerlik göstermektedir. Nitekim Günal ve ark. (2011), \%43'den yüksek kil içeriğine sahip topraklarda OM uzaklaştırılmasının kum fraksiyon boyutlarında, ortalama kil ve kum içeriğinde istatistiksel açıdan önemli düzeyde değişkenliğe neden olduğu rapor edilmiştir. 
Çizelge 4. Farklı kil içeriğine sahip topraklarda organik madde uzaklaştırılmasının parçacık büyüklük dağılımına etkisini değerlendirmek için yapılan eşleştirilmiş t-testi

Table 4. Paired t-test to evaluate the effect of organic matter removal on particle size distribution in soils with different clay contents

\begin{tabular}{|c|c|c|c|c|}
\hline & $\begin{array}{l}\text { Toplam Ortalama } \\
\text { Farkı }(\mathrm{N}=80)\end{array}$ & $\begin{array}{c}\text { Ort. Fark1 } \\
\text { Kil-1 }(\mathrm{N}=32)\end{array}$ & $\begin{array}{c}\text { Ort. Fark1 } \\
\text { Kil-2 }(\mathrm{N}=25)\end{array}$ & $\begin{array}{c}\text { Ort. Fark1 } \\
\text { Kil-3 }(\mathrm{N}=23)\end{array}$ \\
\hline Kil - OM Kil & $-2.64 * *$ & $-3.24 * *$ & $-2.85 * *$ & $-1.45^{*}$ \\
\hline Kum - OM Kum & $3.16 * *$ & $4.01 * *$ & $3.78 * *$ & 1.06 \\
\hline Silt - OM Silt & -0.52 & -0.77 & -0.92 & 0.39 \\
\hline $1000 \mu-$ OM $1000 \mu$ & -0.88 & -0.82 & -1.62 & -0.05 \\
\hline $500 \mu-$ OM $500 \mu$ & 0.371 & $2.45^{*}$ & -0.97 & -1.24 \\
\hline $250 \mu-$ OM $250 \mu$ & $-2.04 *$ & $-2.96^{*}$ & -0.10 & -2.99 \\
\hline $106 \mu-$ OM $106 \mu$ & $2.01 *$ & 1.99 & 2.58 & 1.35 \\
\hline $53 \mu-$ OM $53 \mu$ & 0.53 & -0.67 & 0.11 & 2.93 \\
\hline
\end{tabular}

${ }^{*} \mathrm{P}<0.05$ düzeyinde önemlidir. ${ }^{* *} \mathrm{P}<0.01$ düzeyinde önemlidir. Kil-1: $<\% 40 ;$ Kil-2: \%40-60; Kil-3: >\%60

Hidrojen peroksit ile OM uzaklaştırılması işlemi ile OM içeriği arasındaki ilişkiyi açıklayabilmek amacı ile toprak örnekleri OM içeriklerine göre 0 ile $\leq \% 1$ arasi, $\%>1$ ile $\leq 2$ aras $1,>2$ ile $\geq 4$ aras 1 ve $>\% 4$ şeklinde 4 gruba ayrılmıştır (Çizelge 5).

Organik madde uzaklaştırılmadan önce ve sonra toprak örneklerinin kil içeriği 3. grup örnekler haricinde istatistiksel açıdan önemli düzeyde artmıştır. En büyük farklılık \%3.85 ile 4. grupta yer alan topraklarda iken en düşük değişim $\% 0.87$ ile 3 . grup topraklarda gerçekleşmiştir.

Kum içeriğinin değişimi ise sadece 1 . grupta yer alan topraklarda önemsiz iken diğer tüm OM gruplarında istatistiksel açından anlamlı düzeyde azalmıştır.

Silt içeriği sadece 3. gruptaki topraklarda istatistiksel olarak önemli düzeye artmıştır (Çizelge $5)$.

Çizelge 5. Organik madde içeriğine göre sınıflanan topraklarda organik maddenin uzaklaştırılmasının tekstür bileşenlerine etkisini değerlendirmek için yapılan eşleştirilmiş t-testi

Table 5. Paired t-test to evaluate the effect of organic matter removal on texture components in soils classified with organic matter content

\begin{tabular}{|c|c|c|c|c|c|}
\hline & $\begin{array}{c}\text { Toplam } \\
\text { Ortalama } \\
\text { Fark1 } \\
(\mathrm{N}=80)\end{array}$ & $\begin{array}{l}\text { Ort. Fark1 } \\
\text { OM Grup } 1 \\
(\mathrm{~N}=21)\end{array}$ & $\begin{array}{l}\text { Ort. Fark1 } \\
\text { OM Grup } 2 \\
(\mathrm{~N}=19)\end{array}$ & $\begin{array}{l}\text { Ort. Fark1 } \\
\text { OM Grup } 3 \\
(\mathrm{~N}=20)\end{array}$ & $\begin{array}{l}\text { Ort. Fark1 } \\
\text { OM Grup } 4 \\
(\mathrm{~N}=20)\end{array}$ \\
\hline Kil - OM Kil & $-2.64 * *$ & $-2.36^{* *}$ & $-3.63^{* *}$ & -0.87 & $-3.85 * *$ \\
\hline Kum - OM Kum & $3.16^{* *}$ & 1.57 & $4.13 * *$ & $2.92 * *$ & $4.28 * *$ \\
\hline Silt - OM Silt & -0.52 & 0.79 & -0.50 & $-2.04 * *$ & -0.43 \\
\hline $1000 \mu-$ OM $1000 \mu$ & -0.88 & -1.77 & 0.91 & -1.55 & -0.93 \\
\hline $500 \mu-$ OM $500 \mu$ & 0.371 & 0.735 & 2.25 & -0.16 & 1.37 \\
\hline $250 \mu-$ OM $250 \mu$ & $-2.04 *$ & $-4.82 *$ & -2.80 & 0.30 & -0.51 \\
\hline $106 \mu-$ OM $106 \mu$ & $2.01^{*}$ & -0.02 & 1.10 & $3.77 *$ & $3.43 *$ \\
\hline $53 \mu-$ OM $53 \mu$ & 0.53 & 5.87 & -1.45 & -2.36 & -0.63 \\
\hline
\end{tabular}

*P $<0.05$ düzeyinde önemlidir. ${ }^{* *} \mathrm{P}<0.01$ düzeyinde önemlidir. OM Grup 1: OM içeriği 0 ile $\leq \% 1$ arası; OM Grup 2: $\%>1$ ile $\geq 2$ arasi; OM Grup 3: $>2$ ile $\geq 4$ arasi; OM Grup 4: $>\% 4$

Elonen (1971), organik karbon içeriği \%0.4-0.9 arasında değişen topraklarda, $\mathrm{H}_{2} \mathrm{O}_{2}$ muamelesinin kil fraksiyonlarında önemli bir değişime neden olmadığı bildirilmektedir.

Bununla beraber, organik karbon içeriği \%2.5 ile 19.7 arasında değiş̧en topraklara $\mathrm{H}_{2} \mathrm{O}_{2}$ ile muamele edilmesi sonucu kil fraksiyonunda önemli düzeyde artışlar olduğu rapor edilmiştir.

Kum fraksiyonlarında ise, en önemli farklılığın $106 \mu$ çapındaki elek genişliğinin üzerinde kalan kumların miktarında olduğu belirlenmiştir.
Özellikle 3. ve 4. grupta yer alan toprakların kum içeriklerinde istatistiksel olarak önemli düzeyde $(\mathrm{P}<0.05)$ azalış görülürken, $250 \mu$ boyutundaki kum miktarında 3. grup toprakların haricinde artış meydana gelmiştir.

Ancak bu artı̧̧ sadece 1. grupta \%4.82 ile istatistiksel olarak önemli düzeyde $(\mathrm{P}<0.05)$ iken diğer gruplarda oluşan farklılık önemsiz bulunmuştur. 


\section{Sonuç}

$\mathrm{Bu}$ çalışma tekstür analizi öncesinde $\mathrm{H}_{2} \mathrm{O}_{2}$ ile organik madde uzaklaştırılmasının toprağın kil, silt ve kum içerikleri ile kum fraksiyonlarına etkisini değerlendirmek amacı ile gerçekleştirilmiştir.

Sonuçlar organik madde uzaklaştırılması ile kum ve kil içeriklerinin istatistiksel olarak önemli düzeyde değiştiğini göstermiştir. Organik madde uzaklaştırılması ile kil ve silt içeriği artarken, kum içeriğinde önemli düzeyde azalmıştır.

Kum fraksiyonlarında ise, genelde $250 \mu$ boyutundaki kum miktarındaki artışa karşı1lk $106 \mu$ boyutundaki kum miktarının önemli düzeyde azaldığ 1 tespit edilmiştir.

Kil içeriğinin organik madde içeriğinden bağımsız olarak artarken, kum içeriği \%1'den daha düşük organik madde içeriğine sahip topraklar haricinde azalmıştır.

Sonuçlar, organik maddenin \%1'in üzerinde olduğu her toprakta organik madde uzaklaştırmasının tekstür bileşenlerini önemli düzeyde değiştirdiğini göstermiştir.

Toprağın birçok fonksiyonunun gerçekleşmesinde kritik öneme sahip olan kil ve kum içeriklerinin doğru bir şekilde belirlenmesi, kil ve kum içeriklerini parametre olarak kullanan modellerin ve birçok pedotransfer fonksiyonunun gerçeğe yakın tahminler yapmasını mümkün kılacaktır.

$\mathrm{Bu}$ nedenle, $\% 1$ 'den daha yüksek organik madde içeren topraklarda tekstür analizine başlamadan önce organik madde uzaklaştırmasının standart bir işlem haline getirilmesi önerilmektedir.

\section{Kaynaklar}

Askin, T., Özdemir, N., 2003. Soil bulk density as related to soil particle size distribution and organic matter content. Agriculture 9, 52-56.

Bayat, H., Rastgo, M., Zadeh, M. M., Vereecken, H., 2015. Particle size distribution models, their characteristics and fitting capability. Journal of Hydrology, $\quad 529, \quad 872-889$. https://doi.org/10.1016/j.jhydrol.2015.08.067

Blott S.J., Pye K., 2006. Particle size distribution analysis of sand-sized particles by laser diffraction: an experimental investigation of instrument sensitivity and the effects of particle shape. Sedimentology, 53, 671-685. https://doi.org/10.1111/j.1365-3091.2006.00786.x

Bouyoucos, G.J., 1962. Hydrometer method improved for making particle size analysis of soils. Agronomy Journal 54, 464-465. doi:10.2134/agronj1962.00021962005400050028 $\mathrm{x}$

Brady, N.C., Weil, R.R., 2010. Elements of the Nature and Properties of Soils. Pearson
Educational International, Upper Saddle River, NJ.

Broersma, K., Lavkulich, L., 1980. Organic matter distribution with particle-size in surface horizons of some sombric soils in Vancouver Island. Can. J. Soil Sci. 60 (3), 583-586. https://doi.org/10.4141/cjss80-064

Bronick, C. J., Lal, R., 2005. Soil structure and management: a review. Geoderma, 124(1-2), 322. https://doi.org/10.1016/j.geoderma.2004.03.005

Burgos, P., Madejón, E., Cabrera, F., 2006. Nitrogen mineralization and nitrate leaching of a sandy soil amended with different organic wastes. Waste Manage. Res. 24 (2), 175-182. https://doi.org/10.1177/0734242X06062876

Chiu, C.Y., Chen, T.H., Imberger, K., Tian, G., 2006. Particle size fractionation of fungal and bacterial biomass in subalpine grassland and forest soils. Geoderma $\quad 130 \quad$ (3), 265-271. https://doi.org/10.1016/j.geoderma.2005.01.025

Dobrowolski R., Bieganowski A., Mroczek P., Ryzak M., 2012. Role of periglacial processes in epikarst morphogenesis: a case study from $\mathrm{Che}^{3} \mathrm{~m}$ Chalk Quarry, Lublin Upland, Eastern Poland. Permafrost Periglac. Process., 23(4), 251-266. https://doi.org/10.1002/ppp.1750

Elonen, P., 1971. Particle-size analysis of soil. Acta Agralia Fennica no. 122.

Ersahin, S., Gunal, H., Kutlu, T., Yetgin, B., Coban, S., 2006. Estimating specific surface area and cation exchange capacity in soils using fractal dimension of particlesize distribution. Geoderma 136 (3), 588-597. https://doi.org/10.1016/j.geoderma.2006.04.014

Filgueira, R.R., Fournier, L.L., Cerisola, C.I., Gelati, P., García, M.G., 2006. Particle-size distribution in soils: a critical study of the fractal model validation. Geoderma 134 (3), 327-334. https://doi.org/10.1016/j.geoderma.2006.03.008

Gee, G.W., Bouder, J.W., 1986. Particle Size Analysis. In: A. Clute (Ed.) Methods of Soil Analysis. Part I Agronomy No: 9 Am Soc. of Agron. Madison, Wisconsin, USA.

Gee, G.W, Or, D., 2002. Particle-size analysis. In: Dane JH, Topp GC, editors. Methods of Soil Analysis Part 4-Physical methods. Soil Science Society of America, Inc. Madison, Wisconsin, USA 2002. p. 255-294.

Gray, C.W., Allbrook, R., 2002. Relationships between shrinkage indices and soil properties in some New Zealand soils. Geoderma, 108(3-4), 287-299. https://doi.org/10.1016/S00167061(02)00136-2

Gunal, H., Ersahin, S., Yetgin, B., Kutlu, T., 2008. Use of Chromameter-Measured Color Parameters in Estimating Color-Related Soil Variables. Communications in Soil Science and Plant 
Analysis,

39(5-6),

726-740.

https://doi.org/10.1080/00103620701879422

Gunal, H., Ersahin, S., Uz, B.Y., Budak, M., Acir, N., 2011. Soil particle size distribution and solid fractal dimension as influenced by pretreatments. J. Agr. Sci., 17, 217-229.

Hajnos, M., Calka, A., Józefaciuk, G., 2013. Wettability of mineral soils. Geoderma, 206, 6369.

https://doi.org/10.1016/j.geoderma.2013.04.019

Hamarshid, N.H., Othman, M.A., Hussain, M.A.H., 2010. Effects of soil texture on chemical compositions, microbial populations and carbon mineralization in soil. Egypt. J. Exp. Biol. (Bot.), 6(1), 59-64.

Hillel, D., 1980. Fundamentals of Soil Physics. Academic Press, Inc. (London) Ltd.

Horn, R., Smucker, A., 2005. Structure formation and its consequences for gas and water transport in unsaturated arable and forest soils. Soil \& Tillage Research, 82(1), 5-14. https://doi.org/10.1016/j.still.2005.01.002

Jackson, M.L., 1958. Soil Chemical Analysis. Prentice-Hall Inc., Englowed Cliffts, New Jersey U.S.A.

Jensen, J.L., Schjønning, P., Watts, C.W., Christensen, B.T., Munkholm, L.J., 2017. Soil texture analysis revisited: Removal of organic matter matters more than ever. PLoS ONE 12(5): e0178039.

https://doi.org/10.1371/journal.pone.0178039

Kabala, C., Zapart, J., 2012. Initial soil development and carbon accumulation on moraines of the rapidly retreating Werenskiold Glacier, SW Spitsbergen, Svalbard archipelago. Geoderma, 175-176, 9-20. https://doi.org/10.1016/j.geoderma.2012.01.025

Kacar, B., 1994. Bitki ve Toprağın Kimyasal Analizleri III Toprak Analizleri. Ankara Üni. Zir. Fak. Eğitim Araştırma Geliştirme Vakfı Yayınları No.3.

Karup, D., Moldrup, P., Paradelo, M., Katuwal, S., Norgaard, T., Greve, MH., de Jonge, L. W., 2016. Water and solute transport in agricultural soils predicted by volumetric clay and silt contents. J. Contam. Journal of Hydrology 192, 194-202. https://doi.org/10.1016/j.jconhyd.2016.08.001

Kemper, W.D., Rosenau, R.C., 1986. Aggregate stability and size distribution. In: Klute A, editor. Methods of soil analysis. Part 1. Physical and mineralogical methods. Madison, WI. p 425-42.

Kilmer, V.J., Alexander, L.T., 1949. Methods of making mechanical analyses of soils. Soil Science, 68(1), 15-24.

Kone, B., Yao-Kouamé, A., Ettien, J.B., Oikeh, S., Yoro, G., Diatta, S., 2009. Modelling the relationship between soil color and particle size for soil survey in Ferralsol environments. Soil and Environment, 28(2), 93-105.

Kunze, G.W. Dixon, J.B., 1986. Pretreatment for mineralogical analysis. In: Methods of Soil Analysis: Part 1, Physical and Mineralogical Methods, 2nd edn (ed. A. Klute), pp. 91-100. Agronomy Monograph No 9, American Society of Agronomy, Madison, WI.

Lamorski, K., Pachepsky, Y., Slawiñski, C., 2008. Using support vector machines to develop pedotransfer functions for water retention of soils in Poland. Soil Sci. Soc. Am. J., 72(5), 12431247. http://doi:10.2136/sssaj2007.0280N

Mikutta, R., Kleber, M., Kaiser, K., Jahn, R., 2005. Review: Organic matter removal from soils using hydrogen peroxide, sodium hypochlorite, and disodium peroxodisulfate. Soil Sci. Soc. Am. J. 69 , $120-135$. https://doi.org/10.2136/sssaj2005.0120

Mohammadi, M.H., Meskini-Vishkaee, F., 2013. Predicting soil moisture characteristic curves from continuous particlesize distribution data. Pedosphere, 23(1), 70-80. https://doi.org/10.1016/S1002-0160(12)60081-2

Nelson, D.W., Sommers, L.E., 1982. Methods of Soil Analysis, Part 2. Chemical and Microbiological Properties, Page, A.L., Miller, R.H. Keeney, D.R. (Ed) 2nd Ed. SSS of Am. Inc. Pub., Madison, Wisconsin.

Nimmo, J., 2004. Porosity and pore size distribution. Encycl. Soils Environ. 3, 295- 303.

Polakowski, C., Sochan, A., Bieganowski, A., Ryzak, M., Földényi, R., Tóth, J., 2014. Influence of the sand particle shape on particle size distribution measured by laser diffraction method. International Agrophysics, 28(2), 195-200.

Rhoades, J., Chandavi, D., Lesch, S.F., 1999. Soil Salinity Assessment Methods and Interpretation of Electrical Conductivity Measurement FAO Irrigation and Drainage Paper 57 Rome.

Schjønning, P., Keller, T., Obour, P.B., McBride, R.A., 2017. Predicting soil particle density from clay and soil organic matter contents. Geoderma. 286, 83-87.

https://doi.org/10.1016/j.geoderma.2016.10.020

Scott, E. E., Rothstein, D. E., 2014. The dynamic exchange of dissolved organic matter percolating through six diverse soils. Soil Biology and Biochemistry, 69 , 83-92. https://doi.org/10.1016/j.soilbio.2013.10.052

Sepaskah, A.R., Tafteh, A., 2013. Pedotransfer function for estimation of soil-specific surface area using soil fractal dimension of improved particle-size distribution. Arch. Acker. Pfl. Boden., 59(1), 93-103. https://doi.org/10.1080/03650340.2011.602632

Shi, Z. H., Fang, N. F., Wu, F. Z., Wang, L., Yue, B. J., Wu, G.L., 2012. Soil erosion processes and 
sediment sorting associated with transport mechanisms on steep slopes. Journal of Hydrology, 454, 123-130. https://doi.org/10.1016/j.jhydrol.2012.06.004

Skopp, J. M., 1999. "Physical properties of primary particles." Handbook of Soil Science. Sumner, M. E., (Ed.). A3-17. CRC press.

Stanchi, S.E., Bonifacio, E.Z., Perfect, E., 2008. Chemical and physical treatment effects on aggregate breakup in the 0 - to 2-mm size range. Soil Sci. Soc. Am. J 72(5), 1418-1421. doi:10.2136/sssaj2007.0413N

Walkiewicz, A., Bulak, P., Brzeziñska, M., Włodarczyk, T., Polakowski, C., 2012. Kinetics of methane oxidation in selected mineral soils. International Agrophysics, 26(4), 401-406.

Wilding, L.G., 1985. Spatial Variability: Its Documentation, Accommodation and Implication to Soil Surveys. In: D.R. Nielsen and J. Bouma (Eds), Soil Spatial Variability, Pudoc, Wageningen, pp. 166- 193. 